\title{
A possible control of food intake during pregnancy in the rat
}

\author{
BY BRIAN MORGAN AND MYRON WINICK \\ Institute of Human Nutrition, Columbia University College of Physicians and Surgeons, \\ 701 West 168th Street, New York, New York 10032, USA
}

\section{(Received 3 October 1980 - Accepted 20 March 1981)}

1. Brain hypothalamic concentrations of serotonin and norepinephrine have been implicated in the control of food intake. During pregnancy and lactation a rat dam's food consumption is increased and so a study was performed to ascertain whether this was associated with changes in the hypothalamic content of serotonin and norepinephrine.

2. In the first experiment, forty-eight Sprague Dawley rat dams were given a diet containing $250 \mathrm{~g}$ casein $/ \mathrm{kg}$ adlib. After 2 weeks, eight were killed and their hypothalami analysed for the previously-mentioned neurotransmitters. The rest were mated and coninued on the diet. On each of days 7, 14 and 20 of gestation, day 14 of lactation and 2 weeks after weaning of their pups a further eight dams were killed and their hypothalami assayed as described previously. Food intake was monitored throughout the experimental period.

3. The increased food intake of the dams during gestation and lactation increased to the same extent as elevations in hypothalamic nor epinephrine content and depressions in serotonin content. After lactation food intake returned to pre-pregnancy levels as did the hypothalamic levels of norepinephrine and serotonin.

4. By using the same expermental design but limiting the increase in food intake in pregnancy and lactation to half the expected amount the same changes were found in hypothalamic norepinephrine and serotonin contents.

5. The possibility of hypothalamic neurotransmitter contents controlling food intake is discussed.

During pregnancy and actation the rat dam increases and decreases her food intake at different times. During the first week of gestation there is a reduced food consumption over pre-pregnancy levels. Th.is is followed by a gradual rise until day 20 (Leibowitz, 1970). It is well accepted that the hypothalamus is concerned with the control of food intake.

Local injection of norepinephrine in brain has been shown to stimulate food consumption. Leibowitz has demonstrated that the $\alpha$-receptors in the ventro-medial nuclei of the hypothalamus when stimulated increase food consumption in animals fed ad lib. (Leibowitz, 1970,1973 ). Conversely, injection of serotonin into the perifornical hypothalamic area sometimes causes a small reduction in food intake (Baile, 1974). Drugs that induce serotonin synthesis like 5-hydroxvtryptophan suppress food intake (Blundell \& Lesham, 1974). Similarly, drugs that inisrease the release of serotonin from presynaptic nerves such as p-chloramphetamine and fenfluoramine suppress food intake immediately after their injection (Bizzi et al. 1970; Clineschmidt et al. 1974; Lesham \& Blundell, 1974; Shoulson \& Chase, 1975).

In these experiments we were interested in examining the hypothesis that changes in hypothalamic norepinep.rine and serotonin levels are associated with the changes in food intake of rat dams during pregnancy and lactation.

\section{MATERIALS AND METHODS}

Forty-eight Sprague Dawley rat dams were housed individually and given a diet containing $250 \mathrm{~g}$ casein $/ \mathrm{kg}$ in pelleted form (Table $\mathrm{l}$ ). They also were given free access to drinking water throughout the experiment. After $14 \mathrm{~d}$, eight were killed; the remaining rats were mated. A further eight were killed on days 7,14 and 20 of gestation, day 14 of lactation and $14 \mathrm{~d}$ after weaning of their pt.ps at day 21 of lactation.

All rats were killed at approximately 18.00 hours, their hypothalami removed, weighed and analysed individually for serotonin and norepinephrine using the Jacobowitz \& 
Table 1. Composition $(\mathrm{g} / \mathrm{kg})$ of experimental diets

\begin{tabular}{llr}
\hline \hline & \\
\hline & Constituent & \\
\hline Casein & 250 \\
Maize & 540 \\
Maize oil & 150 \\
& Salt mix & 40 \\
& Vitamin mix ${ }^{\dagger}$ & 20 \\
\hline \hline
\end{tabular}

- Salt mix formulated after Bernhart \& Tomarelli (1966).

+ Composition ( $/ \mathrm{kg}$ diet): retinol $4.0 \mathrm{mg}$, cholecalciferol $3.00 \mu \mathrm{g}$, phylloquinone $1.0 \mathrm{mg}$, tocopheryl acetate $111.75 \mathrm{mg}$, thiamin hydrochloride $10.0 \mathrm{mg}$, nicotinic acid $40.0 \mathrm{mg}$, riboflavin $10.0 \mathrm{mg}$, calcium pantothenate $40.0 \mathrm{mg}$, folic acid $5.0 \mathrm{mg}$, biotin $1.0 \mathrm{mg}$, pyridoxine hydrochloride $10.0 \mathrm{mg}$, vitamin $B_{12} 5.0 \mu \mathrm{g}$, choline $1.0 \mathrm{~g}$. ascorbic acid $75.0 \mathrm{mg}$, cellulose carrier $18.62 \mathrm{~g}$.

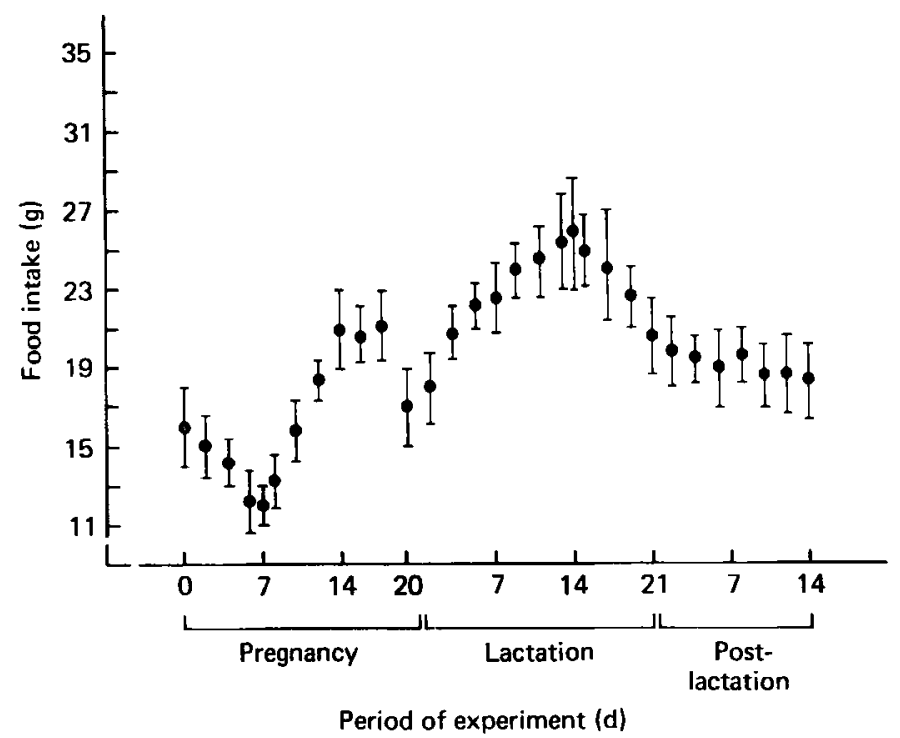

Fig. 1. Food intake measurements (g) of rat dams at different stages of pregnancy and lactation. Values are means with their standard errors represented by vertical bars for eight rats.

Richardson (1977) modification of the catecholamine method of Hogan (Porter et al. 1965) and the serotonin assay of Maickel \& Miller (1966).

The dams that were allowed to proceed throughout the whole of pregnancy had their litters culled to eight pups at birth. Food intakes were measured for all the rats during the $24 \mathrm{~h}$ before their death.

A second experiment was undertaken using essentially the same design as in the previous experiment. In this experiment rat dams were paired for body-weight with the rats used in the first experiment. However, each rat was only permitted to increase its food intake during pregnancy and lactation by one-half of the expected increment based on the food consumption of the dams in the first experiment. As before, the dams were given a diet containing $250 \mathrm{~g}$ casein $/ \mathrm{kg}$, given free access to drinking water and fed ad lib. Eight dams were killed on days 7,14 and 20 of gestation, day 14 of lactation and $14 \mathrm{~d}$ after weaning of their pups at day 21 of lactation. Five control female rats (non-pregnant, non-lactating) 


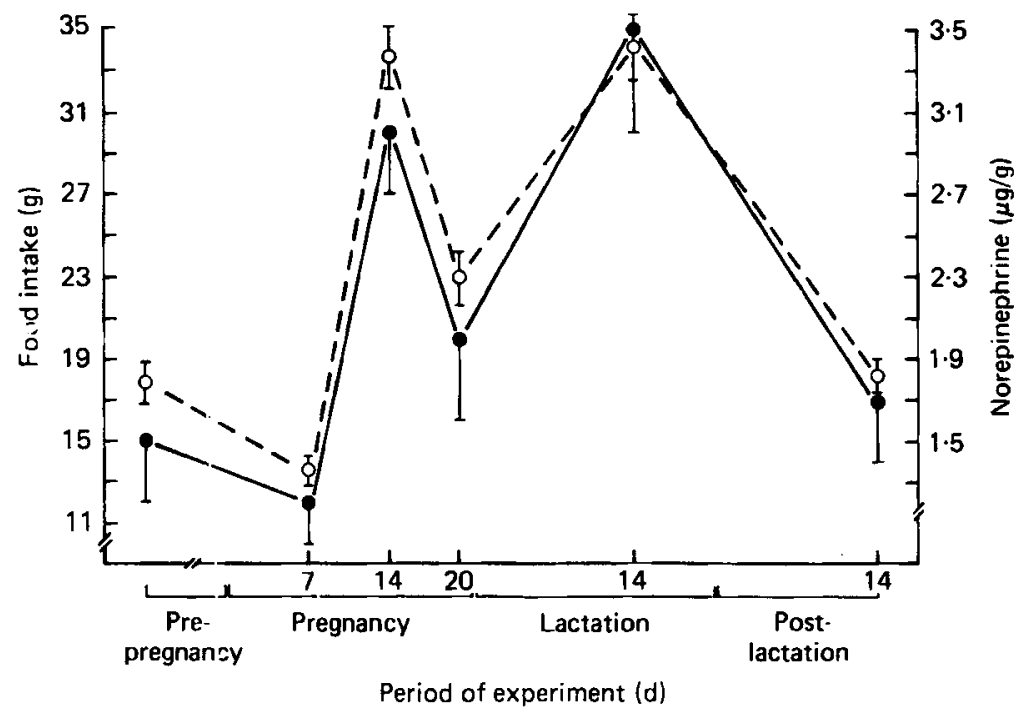

Fig. 2. Hypothalamic norepinephrine concentrations $\left(\mathrm{O}_{---O} ; \mu \mathrm{g} / \mathrm{g}\right)$ and food intake $(\mathrm{O}-\mathrm{O} ; \mathrm{g})$ in rat dams at different stages of pregnancy and lactation. Values are means with their standard errors represented by vertical bars for eight rats.

Table 2. Expt 1. Food intakes and body-weights of rat dams

\begin{tabular}{|c|c|c|c|c|}
\hline \multirow{2}{*}{$\begin{array}{l}\text { Stage of } \\
\text { experiment }\end{array}$} & \multicolumn{2}{|c|}{$\begin{array}{l}\text { Body-wt } \\
\text { (g) }\end{array}$} & \multicolumn{2}{|c|}{$\begin{array}{l}\text { Food intake } \\
(\mathrm{g} / \mathrm{kg} \text { body-wt) }\end{array}$} \\
\hline & Mean & SE & Mean & SE \\
\hline $\begin{array}{l}\text { Pre-pregrancy } \\
\text { Pregnancy: day } 7 \\
\text { day } 14 \\
\text { day } 20 \\
\text { Lactation day } 14 \\
\text { Postlactation: day } 14\end{array}$ & $\begin{array}{l}230 \\
260 \\
283 \\
370 \\
275 \\
265\end{array}$ & $\begin{array}{l}4 \cdot 51 \\
5 \cdot 31 \\
4 \cdot 62 \\
7 \cdot 35 \\
6 \cdot 3 \\
4 \cdot 7\end{array}$ & $\begin{array}{r}6 \cdot 52 \\
4 \cdot 62 \\
10 \cdot 42 \\
5 \cdot 41 \\
12 \cdot 55 \\
6 \cdot 42\end{array}$ & $\begin{array}{l}1 \cdot 15 \\
1.0 \\
0.89 \\
0.76 \\
0.95 \\
1.06\end{array}$ \\
\hline
\end{tabular}

were killed at each time point to control for any methodological differences. The hypothalami of the rats were analysed for serotonin and norepinephrine as in the previous experiment.

\section{RESULTS}

Fig. 1 shows the food intakes of rat dams in the first experiment. There is a gradual rise until day 14 of pregnancy, at which point food consumption levels off until day 20 . At this time point there is a steep decline until birth. After parturition intakes again rise to reach a peak at $14 \mathrm{~d}$ of lactation. At this time, the pups begin to take some of the mother's food and so the demand for milk declines a little. This is reflected in the food eaten by the mother which declines thereafter to return to pre-pregnancy levels soon after the pups are weaned at $21 \mathrm{~d}$ of lactation.

Fig. 2 shows the results of the hypothalamic norepinephrine analyses as well as the food intake measurements on the same days. Food intake and norepinephrine values showed a 


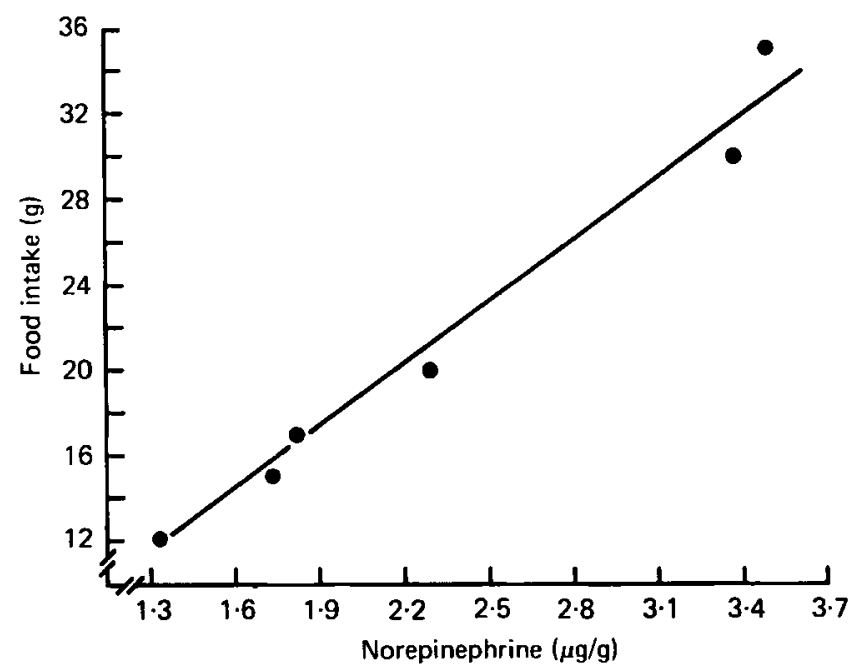

Fig. 3. Regression line of food intake on hypothalamic norepinephrine content. The line represents the result of plotting the values for all forty-eight rat dams during the experiment. The equation of the line is $y=0 \cdot 27+0 \cdot 1 x$.

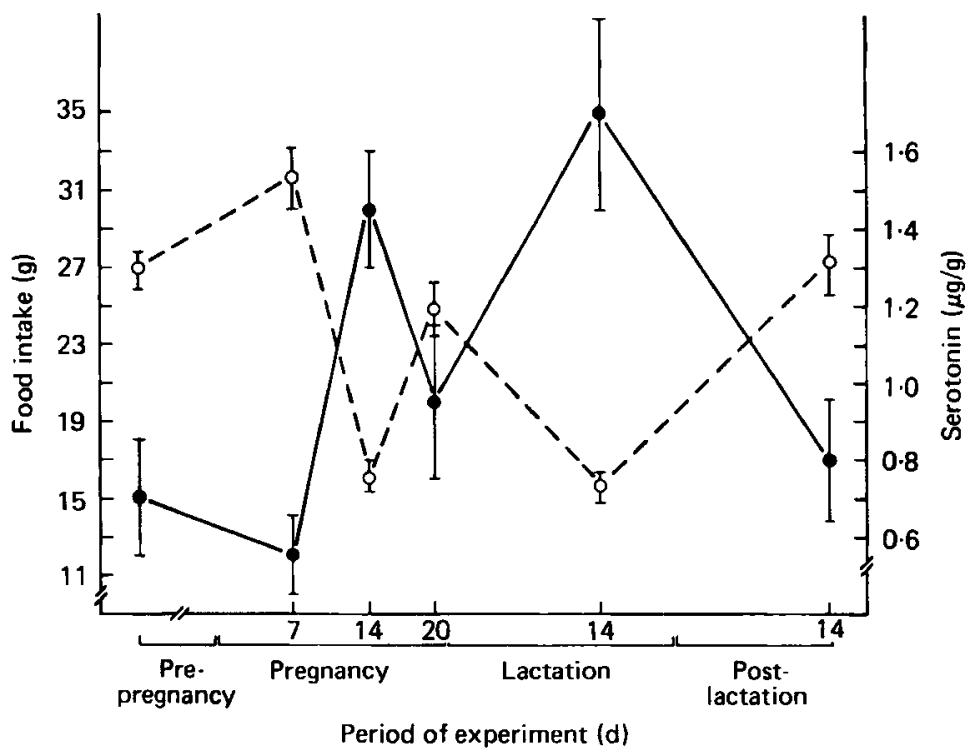

Fig. 4. Hypothalamic serotonin concentrations $(\mathrm{O}--\mathrm{O} ; \mu \mathrm{g} / \mathrm{g})$ and food intake $(\mathrm{O}-\mathrm{O} ; \mathrm{g})$ in rat dams at different stages of pregnancy and lactation. Values are means with their standard errors represented by vertical bars for eight rats.

similar pattern. Both values showed a decline at day 7 of pregnancy compared to pre-pregnancy levels, they peaked at day 14 and then declined at day 20. At day 14 of lactation the levels were again found to be very high. Finally, by day 14 post lactation both had almost completely attained their pre-pregnancy values. Table 2 shows that even when food intake is expressed per kg body-weight, it still increases in the same manner as described previously. Thus the changes in energy intake are a result of the adaptations to pregnancy and not merely to the increased body-weight. 


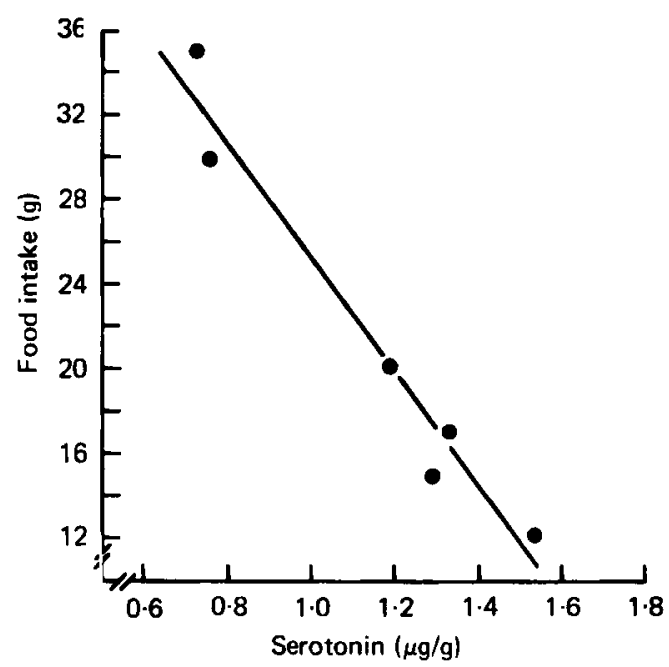

Fig. 5. Regression line of food intake on hypothalamic serotonin content $(\mu \mathrm{g} / \mathrm{g})$. The line represents the result of plotting the values :or all forty-eight rat dams killed during the experiment. The equation of the line is $y=1.89-0.04 x$.

Fig. 3 shows the result of regressing intake on norepinephrine levels. The result is a straight line relationship stowing that as the neurotransmitter level increases so does the food intake and the value of the correlation coefficient was shown to be 0.97 (Bruning \& Kintz, 1968).

Fig. 4 shows the values for the hypothalamic concentrations of serotonin and the food intakes. This shows that when serotonin levels are high food intake is low. Hence serotonin levels are higher on day 7 of pregnancy compared to pre-pregnancy levels and drop to a low level on day 14 when food intake is high. On day 20 of pregnancy, when there was a drop in food irtake, there was a corresponding elevation in serotonin levels. Similarly when food consurnption increases during lactation, serotonin levels decrease. As with norepinephrine, serotonin levels reach their pre-pregnancy levels by $14 \mathrm{~d}$ after the lactational period.

Fig. 5 shows the result of regressing food intake on hypothalamic serotonin levels. It can be seen that as the serotonin levels decrease, food intake increases. The value of the correlation coefficient here :s - 0.96 (Bruning \& Kintz, 1968).

Figs. 6 and 7 illustrate the results of the second experiment presented here. Fig. 6 shows that when the characteristic increment in food intake of a pregnant rat is limited to half of its normal level the changes in hypothalamic norepinephrine content are unaltered in either timing or extent. For comparison the values for non-pregnant rats fed during the same experimental period have been plotted. As shown, the values for food intake and hypothalamic norepinephrine content vary very little during the experiment.

Fig. 7 shows that limiting the food intake has no effect on hypothalamic serotonin levels. Once again, the values for zontrol non-pregnant rats show that neither food intake nor hypothalmic serotonin concentrations varied during the experimental period.

\section{DISCUSSION}

In the first experiment changes in the levels of neurotransmitters in the hypothalamus correlated very well with the changes in food intake characteristic of the rat dam during 


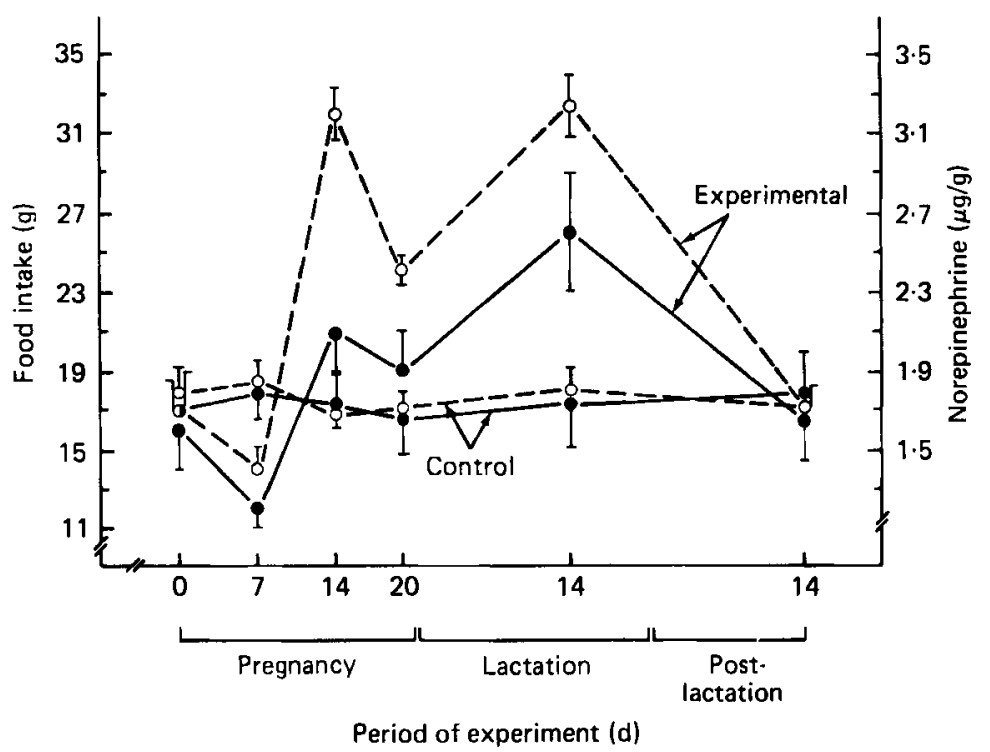

Fig. 6. Hypothalamic norepinephrine concentrations $\left(\mathrm{O}^{---O}, \mu \mathrm{g} / \mathrm{g}\right)$ and food intake $(\mathrm{O}-\mathrm{O} ; \mathrm{g})$ in rat dams, which have had their food intakes limited, at different stages of pregnancy and lactation. Non-pregnant control values are also plotted. Values are means with their standard errors represented by vertical bars for eight experimental and five control rats.

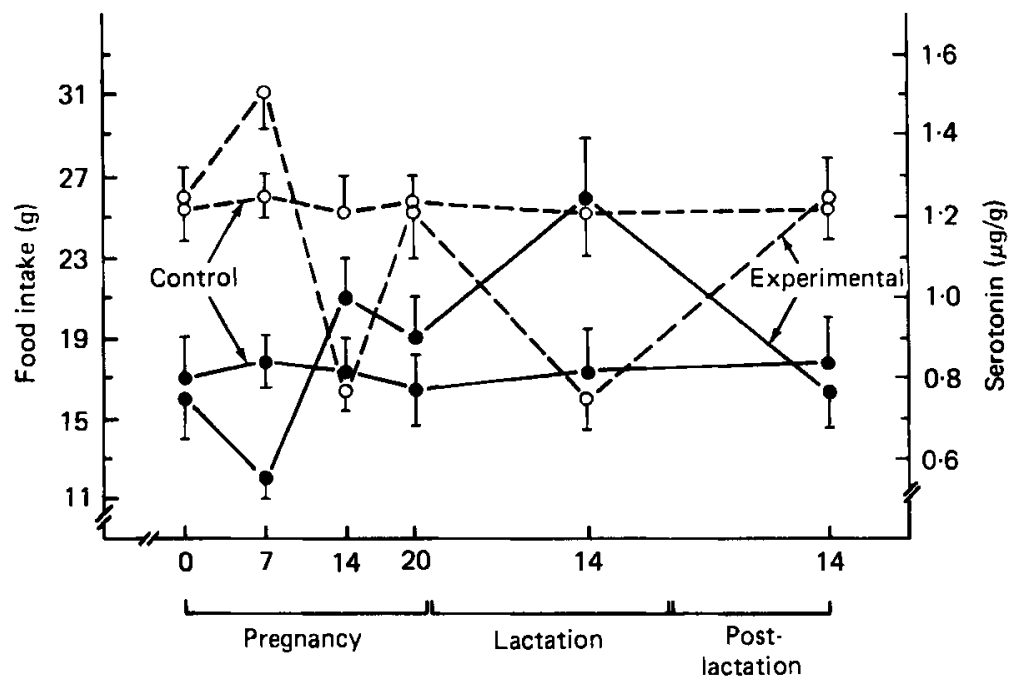

Period of experiment (d)

Fig. 7. Hypothalamic serotonin concentrations $\left(\mathrm{O}_{-}^{--}-\mathrm{O} ; \mu \mathrm{g} / \mathrm{g}\right)$ and food intake $(\mathrm{O}-\mathrm{O} ; \mathrm{g})$ in rat dams, which have had their food intakes limited, at different stages of pregancy and lactation. Non-pregnant control values are also plotted. Values are means with their standard errors represented by vertical bars for eight experimental and five control rats. 


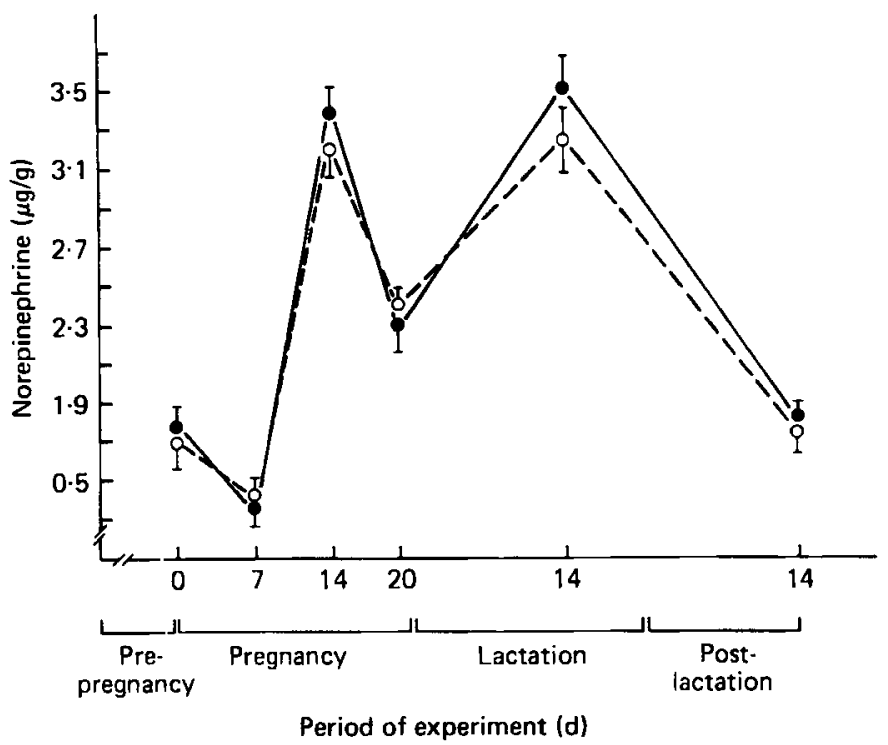

Fig. 8. A comparison of the results obtained, in the ad lib. (O-O) and restricted (O-- $-\mathrm{O})$ experiments, for hypothalamic norepineplirine concentrations $(\mu \mathrm{g} / \mathrm{g})$ at different stages of pregnancy. Values are means with their standard errors r:spresented by vertical bars for eight rats.

pregnancy and lactation. Increasing food intakes correlated with increasing norepinephrine levels and increasing serotonin levels correlated with decreasing food intakes. When food intake was limited in the stcond experiment presented here, the hypothalamic neurotransmitter levels remained essentially the same on every day assayed as in the first experiment. This is shown in Figs. 8 and 9. This would tend to indicate that food intake was the dependent variable.

In feeding-behaviour stıdies in non-pregnant animals the doses of neurotransmitter generally used to induce or suppress eating are usually 2-200 times greater than the whole brain concentrations of :hese substances in normal animals. The total amount of norepinephrine in brains of normal rats usually lies in the range of $0.5-1.5 \mu \mathrm{g}$ (Wurtman, 1977). Since the norepinephrine doses injected into the hypothalamus to elicit or inhibit feeding in most experiments are greater than $20 \mu \mathrm{g}$, one can question whether these effects are related to the physiological concentration of the compound in the brain regions or are a direct result of stimulation of receptors that normally mediate changes in eating behaviour (Lythe, 1977).

There is also a delay of $5-10 \mathrm{~min}$ following local injection of the neurotransmitter before any change can be detected iGrossman, 1960; Leibowitz, 1976). Although you would expect a slight delay while the transmitter diffuses to its site of action, this seems far too long if the substance injected is fulfilling its normal physiological function.

The differing responses cbtained by various workers after injection of neurotransmitter depend on whether the animal is eating or has been fasted. Ritter \& Epstein (1975) showed that small doses of norepinephrine increased meal size by $200 \%$ when the injection was given at the beginning of a spontaneously-initiated meal. However, the same dose had no effect if it were given during inter-meal intervals.

Finally, when giving drugs, we are not sure whether the drug-induced changes in eating behaviour are caused by a direct effect of the drug on the brain's processes of appetite control 


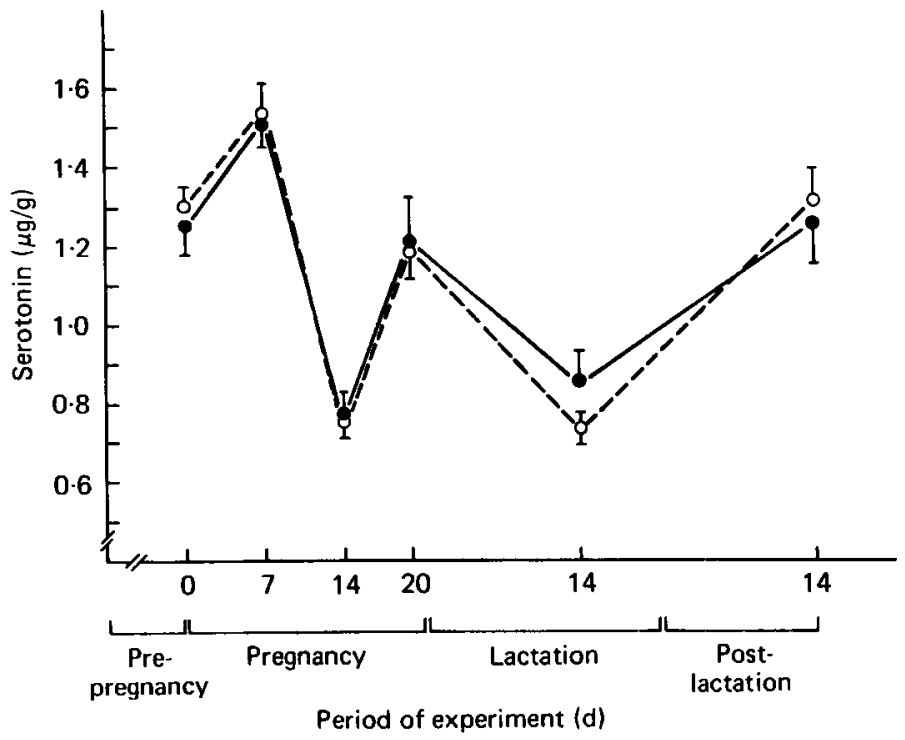

Fig. 9. A comparison of the results obtained, in the ad lib. (O-O) and restricted $\left(\mathrm{O}_{-}-\mathrm{O}^{-} \mathrm{O}\right)$ experiments, for hypothalamic serotonin concentrations $(\mu \mathrm{g} / \mathrm{g})$ at different stages of pregnancy. Values are means with their standard errors represented by vertical bars for eight rats.

or whether the drug has affected a peripheral mechanism which in turn has affected behaviour (Fujimori \& Iwamoto, 1974).

From this brief review it is obvious that injecting neurotransmitters into the brains of experimental animals as a means of further understanding factors responsible for feeding behaviour is fraught with difficulties. The experiment in this paper presents yet another indication that hypothalamic norepinephrine and serotonin levels are intimately related to feeding behaviour. But further we propose that pregnancy might provide an acceptable physiological model to follow changes in neurotransmitter levels associated with altered levels in food consumption.

\section{REFERENCES}

Baile, C. A. (1974). Fedn Proc. Fedn Am. Socs exp. Biol. 33, 1166.

Bernhart, F. \& Tomarelli, R. (1966). J. Nutr. 89, 495.

Bizzi, A., Bonaccorsi, A., Jespersen, S., Jori, A. \& Garaltini, S. (1970). In Amphetamines and Related Compounds, p. 577 [E. Cosia and S. Garattini, editors]. New York: Raven Press.

Blundell, J. E. \& Lesham, M. B. (1974). Eur. J. Pharmac. 28, 81.

Bruning, J. L. \& Kintz, B. L. (1968). Computational Handhook of Statistics, p. 166. Glenview, Illinois: Scott, Foresman and Co.

Clineschmidt, B. V., McGuffin, J. C. \& Werner, A. B. (1974). Eur. J. Pharmac. 27, 313.

Fujimori, K. \& Iwamoto, T. (1974). Neuropharmacology 13, 255.

Grossman, S. P. (1960). Science, N.Y. 132, 301.

Jacobowitz, D. M. \& Richardson, S. J. (1977). Pharmac. Biochem. Behav. 8, 515.

Leibowitz, S. F. (1970). Proc. natn. Acad. Sci. U.S.A. 67, 1063.

Leibowitz, S. F. (1973). In The Neurosciences: Third Study Program, p. 713 [F. O. Schmitt and F. G. Warden, editors]. Cambridge, Mass.: MIT Press.

Leibowitz, S. F. (1976). In Hunger: Basic Mechanisms and Clinical Implications, p. 1 [D. Novin, W. Wyrwicka, and G. Bray, editors]. New York: Raven Press.

Lesham, M. B. \& Blundell, J. E. (1974). J. Pharm. Pharmac. 26, 905.

Lythe, L. D. (1977). In Nutrition and the Brain, vol. 2, p. 1 [R. J. Wurtman and J. J. Wurtman, editors]. New York: Raven Press.

Maickel, R. P. \& Miller, F. P. (1966). Analyt. Chem. 38, 1937. 
Porter, C. C., Totaro, J. A. \& Burcin, A. (1965). J. Pharmac. Exp. Ther. 150, 17.

Ritter, R. C. \& Epstein, A. N. (1975). Proc. natn. Acad. Sci. U.S.A. 72, 3740.

Shoulson, I. \& Chase, T. N. (1975). Clin. Pharmac. Ther. 17, 616.

Wurtman, R. (1977). In Nutrition and the Brain, vol. 2, p. 99 [R. J. Wurtman and J. J. Wurtman, editors]. New York: Raven Press. 